\title{
Persistent Cyfip1 Expression Is Required to Maintain the Adult Subventricular Zone Neurogenic Niche
}

\author{
Christa Whelan Habela, ${ }^{1}$ Ki-Jun Yoon, ${ }^{1,3,4}$ Nam-Shik Kim,,${ }^{1,4}$ Arens Taga, ${ }^{1}$ Kassidy Bell, ${ }^{1}$ ODwight E. Bergles, ${ }^{2}$ \\ Nicholas J. Maragakis, ${ }^{1}$ Guo-li Ming, ${ }^{1,4,5,6,7}$ and Hongjun Song ${ }^{1,4,5,6,8}$ \\ ${ }^{1}$ Department of Neurology, ${ }^{2}$ Solomon H. Snyder Department of Neuroscience, Johns Hopkins University Baltimore, Maryland 21287, ${ }^{3}$ Korea Advanced \\ Institute of Science and Technology, College of Life Science and Bioengineering, Department of Biological Sciences, Daejeon 34141, Republic of Korea, \\ ${ }^{4}$ Department of Neuroscience and Mahoney Institute for Neurosciences, ${ }^{5}$ Institute for Regenerative Medicine, ${ }^{6}$ Department of Cell and Developmental \\ Biology, ${ }^{7}$ Department of Psychiatry, and ${ }^{8}$ The Epigenetics Institute, Perelman School of Medicine, Philadelphia, Pennsylvania 19104
}

Neural stem cells (NSCs) persist throughout life in the subventricular zone (SVZ) neurogenic niche of the lateral ventricles as Type B1 cells in adult mice. Maintaining this population of NSCs depends on the balance between quiescence and self-renewing or self-depleting cell divisions. Interactions between $\mathrm{B} 1$ cells and the surrounding niche are important in regulating this balance, but the mechanisms governing these processes have not been fully elucidated. The cytoplasmic FMRP-interacting protein (Cyfip1) regulates apical-basal polarity in the embryonic brain. Loss of Cyfip1 during embryonic development in mice disrupts the embryonic niche and affects cortical neurogenesis. However, a direct role for Cyfip1 in the regulation of adult NSCs has not been established. Here, we demonstrate that Cyfip1 expression is preferentially localized to B1 cells in the adult mouse SVZ. Loss of Cyfip1 in the embryonic mouse brain results in altered adult SVZ architecture and expansion of the adult B1 cell population at the ventricular surface. Furthermore, acute deletion of Cyfip 1 in adult NSCs results in a rapid change in adherens junction proteins as well as increased proliferation and number of B1 cells at the ventricular surface. Together, these data indicate that Cyfip1 plays a critical role in the formation and maintenance of the adult SVZ niche; furthermore, deletion of Cyfip1 unleashes the capacity of adult B1 cells for symmetric renewal to increase the adult NSC pool.

Key words: adult neurogenesis; Cyfip1; neural stem cells; niche; self-renewal; subventricular zone

Significance Statement

Neural stem cells (NSCs) persist in the subventricular zone of the lateral ventricles in adult mammals, and the size of this population is determined by the balance between quiescence and self-depleting or renewing cell division. The mechanisms regulating these processes are not fully understood. This study establishes that the cytoplasmic FMRP interacting protein 1 (Cyfip1) regulates NSC fate decisions in the adult subventricular zone and adult NSCs that are quiescent or typically undergo self-depleting divisions retain the ability to self-renew. These results contribute to our understanding of how adult NSCs are regulated throughout life and has potential implications for human brain disorders.

\section{Introduction}

Neural stem cells (NSCs) persist in the subventricular zone (SVZ) of the lateral ventricles into adulthood in mammals (Altman, 1969; Doetsch et al., 1999; Bond et al., 2015). The adult SVZ

Received Sept. 17, 2019; revised Jan. 7, 2020; accepted Jan. 21, 2020.

Author contributions: C.W.H., D.E.B., N.J.M., G.-I.M., and H.S. designed research; C.W.H., A.T., and K.B. performed research;C.W.H., K.-J.Y., A.T., D.E.B., N.J.M., G.-I.M., and H.S. analyzed data; C.W.H., D.E.B., and N.J.M. wrote the first draft of the paper; C.W.H. edited the paper; C.W.H., G.-I.M., and H.S. wrote the paper; K.-J.Y. and N.-S.K. contributed unpublished reagents/analytic tools.

This work was supported by National Institutes of Health Grants R25NS065729 and K12NS098482 to C.W.H., R37NS047344 to H.S., and R35NS097370 to G-I.M., SFARI 308988 to H.S., and DOD W81XWH1810174 ALSRP to N.J.M. The Nestin-CreER animals were kindly provided by Gordon Fishell. We thank the members of the H.S. and G.-I.M. laboratories for feedback and technical support, in particular Kim Christian, Daniel Berg, Allison Bond, Tong $\mathrm{Ma}$, Yi Zhou, Fadi Jacob, and Jordan Schnoll.

The authors declare no competing financial interests. recapitulates the developmental NSC niche with an apical-basal polarity of NSCs, referred to as Type B1 cells (Lois and AlvarezBuylla, 1993; Doetsch et al., 1999). The cell bodies of B1 cells lie beneath the ependymal cell layer and undergo symmetric selfrenewing divisions to maintain their population or self-depleting divisions to generate olfactory bulb interneurons or oligodendrocyte precursors (Lois and Alvarez-Buylla, 1993, 1994; Rousselot et al., 1995; Parras et al., 2004; Menn et al., 2006; Obernier et al., 2018). Disruption of the SVZ niche leads to alterations in B1 cell proliferation as well as neuronal and oligodendrocyte genesis

Correspondence should be addressed to Hongjun Song at shongjun@pennmedicine.upenn.edu or Christa Whelan Habela at chabela1@jhmi.edu.

https://doi.org/10.1523/JNEUROSCI.2249-19.2020

Copyright $\odot 2020$ the authors 
(Jiménez et al., 2009; Kokovay et al., 2012; Relucio et al., 2012). The niche structure changes with age as B1 cells are depleted (Shook et al., 2012; Obernier et al., 2018), but the cellular mechanisms regulating niche maintenance and B1 cell fate in the adult brain have still not been fully elucidated.

Type B1 cells project apical processes to the ventricular surface and basal processes to the vasculature underlying the adult SVZ. At the ventricle, the apical processes are surrounded by ependymal cells forming an epithelial surface and oriented in a pinwheel-type formation around the apical processes (Doetsch et al., 1999; Mercier et al., 2002; Alvarez-Buylla and Lim, 2004; Mirzadeh et al., 2008). Central to the niche structure in both the embryo and adult is the maintenance of apical-basal polarity (Yoon et al., 2014; Bizzotto and Francis, 2015; Lian and Sheen, 2015; O'Leary et al., 2017). During embryonic development, radial glial cells (RGCs) make apical connections to the ventricular surface and basal projections to the pia, and the orientation of the division plane along the apical-basal axis regulates the fate of daughter cells (Kosodo et al., 2004; Götz and Huttner, 2005). This polarity is determined by the presence of adherens junctions, and the loss of junction integrity during fetal development leads to alterations in cellular polarity and abnormal neural development (Ferland et al., 2009; Yoon et al., 2014; Bizzotto and Francis, 2015; Guerra et al., 2015; Lian and Sheen, 2015; O'Leary et al., 2017).

The stability of adherens junctions depends on cadherins interacting with the cytoplasmic actin ring (Verma et al., 2012; Priya and Yap, 2015; O'Leary et al., 2017). This process is mediated by Arp2/3-dependent actin nucleation and the WAVE regulatory complex (Verma et al., 2012; Wang et al., 2016). Cytoplasmic FMRP interacting protein1 (Cyfip1) interacts with Rac-GTP to cleave the WAVE regulatory complex, resulting in actin polymerization. Cyfip1 regulates apical-basal polarity, and its loss during the embryonic development results in adherens junction deficits (Yoon et al., 2014). Adult Cyfip1 haploinsufficient mice exhibit impaired myelination and a decreased number of oligodendrocytes in the corpus callosum as well as behavioral abnormalities (Domínguez-Iturza et al., 2019; A. I. Silva et al., 2019b).

In this study, we show persistent expression of Cyfip1 in Type B1 cells of the adult SVZ in mice with prominent localization to the apical processes projecting to the ventricular surface. Deletion of Cyfip1 during embryonic development results in an expansion of the B1 cell population, as well as altered localization and increased proliferation rates in the adult SVZ. Acute loss of Cyfip1 in the adult SVZ NSCs is sufficient to alter the localization and increase proliferation rates of B1 cells, suggesting that Cyfip 1 suppresses symmetric B1 cell expansion in adult mice. Changes in adherens junction protein localization parallel decreases in $\mathrm{Cy}-$ fipl expression and support an underlying loss of adherens junction stabilization.

\section{Materials and Methods}

Animals. All transgenic animals were crossed on a C57BL/6 background. The Nestin-CreER animals were kindly provided by Gordon Fishell (Balordi and Fishell, 2007). Nestin-Cre (JAX stock \#003771: B6.Cg-Tg(Nescre) $1 \mathrm{Kln} / \mathrm{J}$ ) (Tronche et al., 1999; Giusti et al., 2014) and $m$ Tm $G$ reporter mice (stock \#007676: B6.129(Cg)-Gt(ROSA)26Sortm4(ACTB-tdTomato,-EGFP)Luo/J) (Muzumdar et al., 2007) were obtained from the The Jackson Laboratory.

To generate a $C y f i p 1$ floxed allele $\left(C y f i p 1^{f}\right)$, a targeting vector was designed to insert a loxP sequence in front of exon 2 as well as a positive selection marker (PGK promoter-driven, neomycin-resistant gene) together with another loxP sequence next to exon 5 . This was constructed by recombineering as described previously (Liu et al., 2003). Specifically, an $11.9 \mathrm{~kb}$ genome fragment containing exon 2 to exon 5 from $129 \mathrm{~Sv}$ BAC clone (bMQ182K14, Source Bioscience) was retrieved into a PL253 plasmid containing a negative selection marker ( $\mathrm{MC} 1$ promoter driven thymidine kinase gene) using homologous recombination. A loxP sequence and an Flpe-PGK-EM7-Neo-Flpe-loxP cassette were sequentially inserted into the engineered PL253, resulting in 6.0 and $1.0 \mathrm{~kb}$ homology arms. The targeting vector was linearized and electroporated into 129 S4/Sv Jae embryonic stem cells (Transgenic Core Laboratory in Johns Hopkins School of Medicine), and homologous recombination was confirmed by PCR screening. Targeted clones were injected into C57BL/6J blastocysts, which were subsequently transferred into pseudo-pregnant foster mothers. Confirmation of germline transmission of the floxed allele and routine genotyping were performed by PCR screening on tail genomic DNA (wt, $470 \mathrm{bp}$; floxed, $520 \mathrm{bp}$ ) using DNA primers as follows: 5'-GCACCTCTCTGCATTTCTGT-3' and 5'-GCACCAATCAAGTGTT TTCC-3'

For conditional $\mathrm{KO}$ (cKO) experiments, homozygous Cyfip $1^{f / f}$ animals were crossed with animals heterozygous for Nestin-Cre to generate Nestin-Cre:Cyfip $1^{f / f}$ males that were heterozygous for Nestin-Cre with homozygous floxed Cyfip1 alleles. These were subsequently bred with Cyfip $1^{f / f}$ females, resulting in 50\% control $\left(C y f p 1^{f / f}\right)$ and $50 \% \mathrm{cKO}$ animals (Nestin-Cre:Cyfip $1^{f f}$ ). Inducible breeding pairs were made up of Nestin-CreER:Cyfip $1^{+/ f}: m T m G$ males crossed with Cyfip $1^{+/ f}: m T m G$ females. The $m T m G$ allele was either heterozygous or homozygous in experimental animals.

All experiments involving animals were approved by the Animal Care and Use Committee at Johns Hopkins University. Both male and female animals were used for experiments. Animals were housed under $14 \mathrm{~h}$ light/10 h dark housing conditions with standard diets and water ad libitum.

Immunohistochemistry. Anesthetized animals were perfused with PBS followed by $4 \%$ PFA. Brains were removed from skulls and placed in $4 \%$ PFA overnight and no longer than $24 \mathrm{~h}$ at $4^{\circ} \mathrm{C}$. They were then washed one time with $\mathrm{PBS}$ and placed in a $30 \%$ sucrose in PBS at $4^{\circ} \mathrm{C}$ for a minimum of $48 \mathrm{~h}$ before sectioning. Serial coronal brain sections were prepared using a sliding microtome (Leica Microsystems, SM2010R) or a cryostat (Thermo Fisher Scientific, HM 505 and an HM 550) after brains were frozen in either 30\% sucrose solution or OCT freeze solution (Sigma Millipore). Sections were stored frozen in multiwell plates containing antifreeze solution (300 g sucrose, $300 \mathrm{ml}$ ethylene glycol, $500 \mathrm{ml}$ $0.1 \mathrm{M}$ PBS). Before antibody immunostaining, antifreeze solution was removed and sections were washed 2 times with PBS. Antibody solutions were made up of $5 \%$ donkey or goat serum, $3 \%$ BSA, and $0.05 \%$ Triton $\mathrm{X}-100$ in PBS or TBS. Primary antibodies were incubated at $4^{\circ} \mathrm{C}$ for 24 to $72 \mathrm{~h}$. Sections were washed 3 times in $0.05 \%$ Triton X-100 in PBS solution before secondary antibody application. Secondary antibodies were diluted in the above-described antibody solution using goat AlexaFluor$488,-555,-568$, and -647 secondary antibodies (Thermo Fisher Scientific) at 1:400 dilutions in antibody solution with $5 \%$ goat serum or donkey Cy2, Cy3, and Cy5 antibodies (Jackson ImmunoResearch Laboratories) at 1:250 dilution in antibody solution containing 5\% donkey serum. Secondary antibody solutions were incubated either at room temperature for $2-4 \mathrm{~h}$ or overnight at $4^{\circ} \mathrm{C}$. Hoechst 33342 (Sigma Millipore) or DAPI (Roche Diagnostics) nuclear stains were added to the secondary antibody solutions. For antibodies that required antigen retrieval, brain sections were incubated in $1 \times$ target retrieval solution (Agilent Technologies; Dako) or sodium acetate buffer, $\mathrm{pH} 6$ (Sigma Millipore) at $95^{\circ} \mathrm{C}$ for $20 \mathrm{~min}$ and then room temperature for $20 \mathrm{~min}$ before staining. If GFP staining was required, anti-GFP primary and secondary antibody staining was conducted before the antigen retrieval step. Tissue was mounted on Superfrost or Superfrost Plus slides (Thermo Fisher Scientific) and coverslipped with $2.5 \%$ PVA/DABCO mounting media (Sigma Millipore) or ProLong Antifade mounting media (Thermo Fisher Scientific). Specific antibodies are noted in Results and include the following: mouse anti- $\beta$-catenin (BD Biosciences, catalog \#610153), mouse anti- $\gamma$-tubulin (Abcam, catalog \#ab11316), rabbit anti-GFAP (Dako, catalog \#Z0334), rabbit anti-Cyfip1 (Millipore-Sigma, catalog \#Ab6046), rabbit anti- $\beta$-catenin (Thermo Fisher Scientific, catalog \#PA5-16762), chicken anti-GFP (Aves, catalog \#NC9510598), mouse 
anti-N-cadherin (Invitrogen, catalog \#981235A), rabbit anti-S100 $\beta$ (Sigma Millipore, catalog \#HPA015768), mouse anti-S100 $\beta$ (Sigma Millipore, catalog \#AMAB91038), goat anti-Sox2 (Santa Cruz Biotechnology, catalog \#SC17320), rabbit anti-hASH1 (Cosmo Bio, catalog \#SK-T01-003), and rabbit anti-Doublecortin (Dcx) (Cell Signaling Technology, catalog \#4604S).

Whole-mount preparation. Whole-mount preparations of the ventricular wall were prepared using a protocol modified from that published by Mirzadeh et al. (2010). The one modification made was that animals were perfused with $4 \%$ PFA before starting the dissection rather than afterward. Immunostaining of the whole-mount sections was performed as described above.

Cell proliferation quantification. Cells undergoing DNA replication in S phase were identified by incorporation of 5-ethynyl-2'-deoxyuridine (EdU) (Sigma Millipore, catalog \#900584). A stock concentration of 32.5 mM EdU was made by adding EdU to sterile saline solution with the addition of $1: 10005 \mathrm{M} \mathrm{NaOH}$ and heating to $42^{\circ} \mathrm{C}$ for $30-60 \mathrm{~min}$ to dissolve. Stock solutions were stored at $-80^{\circ} \mathrm{C}$. Two to 24 hours before perfusion, the solution was warmed to $37^{\circ} \mathrm{C}$, and intraperitoneal injections were conducted on 56- to 84-d-old animals for a final dose of 200 $\mathrm{mg} / \mathrm{kg}$ body weight. After perfusion and antibody staining, the standard commercial protocol for the Click-iT Plus EdU Cell Proliferation Kit for Imaging (Thermo Fisher Scientific, catalog \#C10639) was used to fluorescently label the EdU incorporated into the newly synthesized DNA. 3D tiled images were obtained of the sections, and images were reconstructed in Imaris 3D software (Bitplane), ImageJ Software (National Institutes of Health), or ZEN software (Carl Zeiss). EdU ${ }^{+}$cell numbers were manually quantified based on the presence of EdU fluorescence in the cell nuclei.

Tamoxifen injection. A stock solution of $66.7 \mathrm{mg} / \mathrm{ml}$ of tamoxifen in a 5:1 solution of corn oil and ethanol was prepared as previously described (Berg et al., 2019). To dissolve the tamoxifen in the corn oil and ethanol solution, it was heated to $37^{\circ} \mathrm{C}$ with intermittent vortexing. Stock concentrations were stored at $-80^{\circ} \mathrm{C}$. Before use, tamoxifen was warmed to $37^{\circ} \mathrm{C}$ and then injected into the intraperitoneal space of P56 to P84 NesCreER: $m$ Tm $G$ animals with or without Cyfip1 floxed at a final concentration of $248 \mathrm{mg} / \mathrm{kg}$ body weight. Animals underwent intracardiac perfusion with 4\% PFA 2 to $8 \mathrm{~d}$ post injection (dpi).

Image acquisition, processing, and quantification. Brain sections were imaged on a Carl Zeiss LSM 800, a Carl Zeiss LSM 710, or a Carl Zeiss 800 Airyscan confocal microscope using Zen Software (Carl Zeiss). Lowmagnification images were acquired with $10 \times$ or $20 \times$ air objectives. High-magnification images were acquired with $40 \times$ or $63 \times$ oilimmersion objectives. $z$ stacks were obtained using the optimal interslice distance for the objective. For quantitative and qualitative experiments in which a control and an experimental condition were being compared, equal settings of laser intensity, pinhole aperture, and interslice distance for $z$ stacks were maintained as constant between conditions within the same experiment whenever possible. For larger field of view, multiple tiled sections were obtained and stitched together before exporting for analysis. 3D reconstructions were generating using Imaris software 7.6 (Bitplane). Quantification of fluorescence intensity was measured in Photoshop (Adobe) or ImageJ software (National Institutes of Health). Quantification of the number of cells expressing different cell markers was determined using Imaris 7.6, Zen, or ImageJ software. Image preparation was conducted in Photoshop (Adobe). Any modifications to brightness or contrast of images were applied equally to control and experimental images.

Quantification and statistical analyses. All data are presented as the mean \pm SEM for single comparisons using $t$ tests. For experiments with multiple comparisons and for paired analysis, the mean difference $\pm \mathrm{SE}$ of the differences was reported. Unless otherwise noted in Results, in cases where coronal sections were analyzed quantitatively, the average of three sections spaced $240 \mu \mathrm{m}$ apart was determined for each animal in the experimental population; $n$ indicates the number of animals. Quantification was performed by a person who was blinded to the animal genotype at the time of imaging and quantification for all figures. Statis- tical analysis was performed using Prism 7 (GraphPad Software). For experiments with only 2 conditions, a two-tailed Student's $t$ test was used for statistical analysis. Unless otherwise noted in Results and figure legends, data were unpaired. For comparisons between multiple groups, a one-way ANOVA followed by the appropriate multiple-comparisons tests were used (Sidak's for comparison between groups, Tukey's for comparison with a control or single value). Sample sizes were not predetermined using statistical methods. The percent margin of error based on published SDs from similar studies for a $95 \%$ CI is $5.5 \%$ for $n=3$ and $3.3 \%$ for $n=8$ animals per condition.

\section{Results \\ Cyfip1 expression persists in the neurogenic niche of the adult SVZ}

To determine whether Cyfip1 is persistently expressed in the neurogenic niche of the adult SVZ, we examined whole-mount preparations as well as coronal sections from C57BL/6 mice between postnatal day 56 and 70 (Fig. $1 A$ ). The SVZ niche at this age is characterized by a unique organization. Type B1 cells express the intermediate filament protein GFAP (Glial Fibrillary Acidic Protein) (Garcia et al., 2004). B1 cells send GFAP ${ }^{+}$apical projections to the ventricular surface forming the hub of the neurogenic niche architecture (Fig. 1B) (Mirzadeh et al., 2008). When viewed en face from the ventricular surface in whole-mount preparations (Fig. $1 C, D$, surface, $E, 5 \mu \mathrm{m}$ below the surface), the apical processes of the GFAP ${ }^{+} \mathrm{B} 1$ cells (Fig. $1 B$, "b," $C$, arrowhead) are surrounded by epithelial-like ependymal cells containing $\gamma$-tubulin ${ }^{+}$cilia (Fig. 1B, "e1" and "e2," C, arrow) forming a "pinwheel" structure. Cell-cell junctions are demarcated by $\beta$-catenin or N-cadherin localized to adherens junctions (Fig. $1 C, E)$. Cell bodies of B1 cells lie beneath the ventricular surface in the SVZ (Fig. $1 B, E$ ).

Immunostaining for Cyfip1 demonstrates that it is expressed in the SVZ of the adult mouse (Fig. $1 D-F$ ). The expression is at the highest levels in $\mathrm{B} 1$ cells and is localized to the apical processes of $\mathrm{B} 1$ cells at the ventricular surface (Fig. $1 D$, arrowheads) as well as cell bodies of $\mathrm{B} 1$ cells below the surface (Fig. $1 E$ ). It is localized to GFAP-expressing cells in discrete clusters at the surface (Fig. $1 D$, arrowheads). Below the ventricular surface, Cyfip 1 staining is present in the cell bodies of $\mathrm{GFAP}^{+}$cells and overlaps with $\mathrm{N}$-cadherin immunostaining at cell membranes (Fig. $1 E$ ) and at lower levels in the $\mathrm{S} 100 \beta^{+} \mathrm{GFAP}^{+}$cells (Fig. $1 F$ ), which represent mature astrocytes (A). In contrast, there is no detectable Cyfip 1 expression in the majority of $\mathrm{S} 100 \beta^{+} \mathrm{GFAP}^{-}$ependymal cells (E) at the ventricular surface (Fig. $1 F$, arrowheads). This specific expression in $\mathrm{GFAP}^{+}$cells and exclusion from ependymal cells were confirmed with quantification (B1 vs E mean difference $=0.725,95 \%$ CI of difference [0.557, 0.893], $p<0.0001$; $\mathrm{A}$ vs $\mathrm{E}$ mean difference $=0.633,95 \%$ CI $[0.465,0.801], p<$ $0.0001 ; \mathrm{B} 1$ vs $\mathrm{A}$ mean difference $=0.0925,95 \% \mathrm{CI}[-0.075$, $0.2604], p=0.339$; one-way ANOVA followed by Tukey's multiple-comparisons test; 616 cells from $n=5$ mice; Fig. $1 G$ ). This result indicates that Cyfip 1 is persistently expressed and is specifically restricted to the $\mathrm{GFAP}^{+} \mathrm{B} 1$ cells and astrocytes of the adult SVZ.

\section{Loss of Cyfip1 expression alters the cellular composition of the ventricular surface in adult mice}

Persistent expression of the Cyfip1 protein in the adult SVZ and the preferential localization of Cyfip1 to B1 cells at the center of the pinwheel niche suggest its potential role in regulating $\mathrm{B} 1$ cells in the adult niche. Germline deletion of Cyfip1 is embryonic lethal (Pathania et al., 2014). Therefore, we generated a cKO animal using Cyfip $1^{\mathrm{f} / \mathrm{f}}$ animals and a Cre-lox system in which Cre expres- 
A whole mount
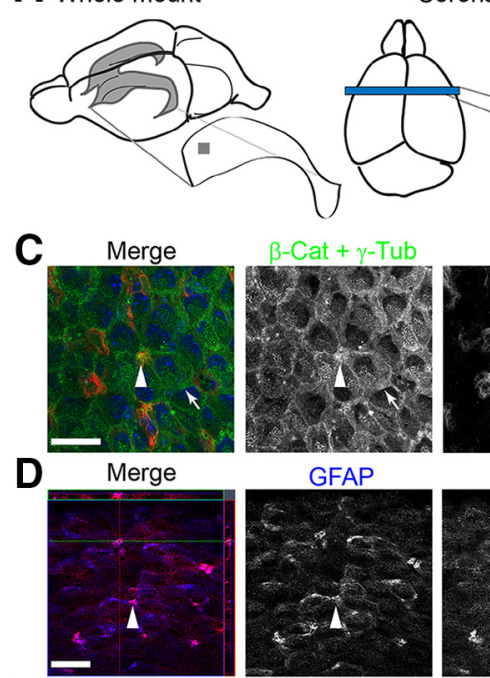

E

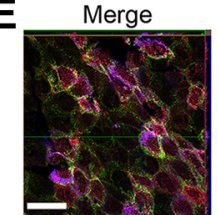

F Merge GFAP
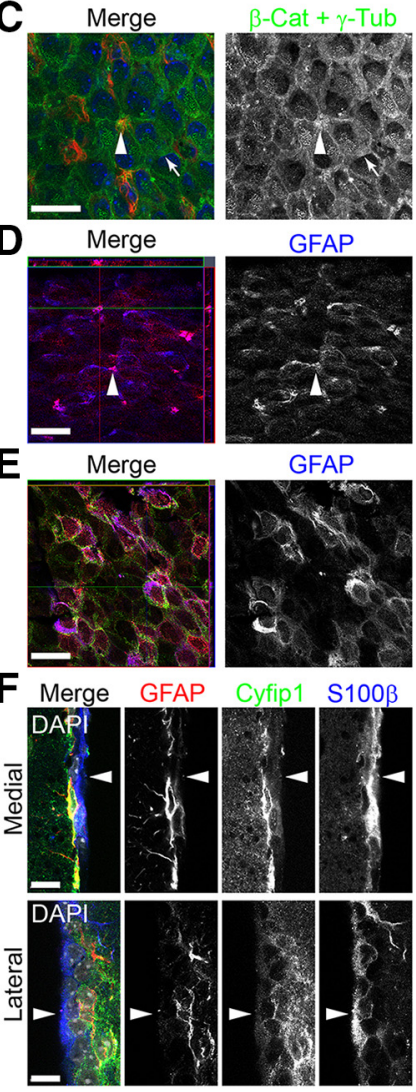

GFAP

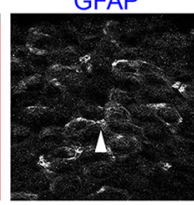

GFAP

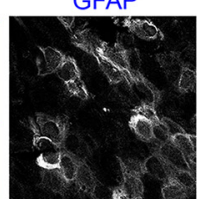

$\mathrm{S} 100 \beta$ G
Coronal

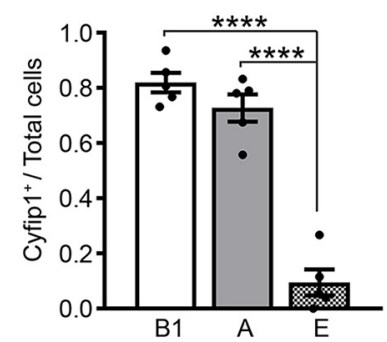

Figure 1. Cyfip1 is expressed in B1 cells of the adult SVZ. A, Diagrammatic illustration of the whole-mount and coronal preparations used for analysis in this study. Gray squares represent the region for the 3D image in $\boldsymbol{B} . \boldsymbol{B}, 3 \mathrm{D}$ diagram of the cellular composition of the adult SVZ. e1, E1 ependymal cells; e2, E2 ependymal cells; b, Type B1 cells; c, Type C transient amplifying cells; a, migratory neuroblasts. Model is based on that of Mirzadeh et al. (2008). C, Sample confocal images of the whole-mount preparation of the dorsolateral surface of the lateral ventricle of a control adult animal with immunofluorescent staining for $\beta$-catenin and $\gamma$-tubulin (green), GFAP (red), and DAPI (blue) in the merged image. Arrowhead indicates GFAP ${ }^{+}$projection at the center of a pinwheel formation. Arrow indicates an ependymal cell forming a blade of the same pinwheel formation. $\boldsymbol{D}$, Sample confocal images of immunofluorescent staining of GFAP (blue) and Cyfip1 (red) on the dorsolateral ventricular surface with pictorial representation of the architecture in the last panel. Arrowheads indicate apical GFAP ${ }^{+}$projections at the center of the pinwheels. Merged panel is an orthographic projection. $\boldsymbol{E}$, Sample confocal images of immunostaining of GFAP (blue), Cyfip1 (red), and N-cadherin (green) $5 \mu \mathrm{m}$ below the ventricular surface. Merged panel is an orthographic projection. $\boldsymbol{F}$, Sample confocal images of coronal sections immunostained for GFAP (red), Cyfip1 (green), $5100 \beta$ (blue), and DAPI (gray in the merged image). Images are examples from the medial (top) and the lateral (bottom) ventricular walls. Arrowheads indicate $S 100 \beta^{+} \mathrm{GFAP}^{-}$Cyfip $1^{-}$ependymal cells surrounded by Cyfip $1^{+} \mathrm{GFAP}^{+} \mathrm{S} 100 \beta^{+}$astrocytes and Cyfip $1^{+} \mathrm{GFAP}^{+} \mathrm{S} 100 \beta^{-}$B1 cells. Scale bars: $\mathbf{C}-\boldsymbol{E}$, $20 \mu \mathrm{m} ; \boldsymbol{F}, 10 \mu \mathrm{m}$. All images are representative of similar immunostaining observed in a minimum of 4 animals. $G$, Quantification of the number of cells that are Cyfip $1^{+}$in each of three cell types in the adult SVZ niche. B1, GFAP ${ }^{+} \mathrm{S} 100 \beta^{-}$Type B1 cells; A, GFAP ${ }^{+} \mathrm{S} 100 \beta^{+}$ astrocytes; E, GFAP ${ }^{-} \mathrm{S} 100 \beta^{+}$ependymal cells. Ratios represent the total number of each cell type divided by the number of Cyfip $1^{+}$cells of that type. Quantification is based on 616 cells from coronal sections as in $\boldsymbol{F}$. Each dot represents value of the mean from 1 animal. Bars indicate mean \pm SEM; $n=5$ animals. ${ }^{* * *} p<0.0001$ (one-way ANOVA followed by Tukey's multiplecomparisons test).
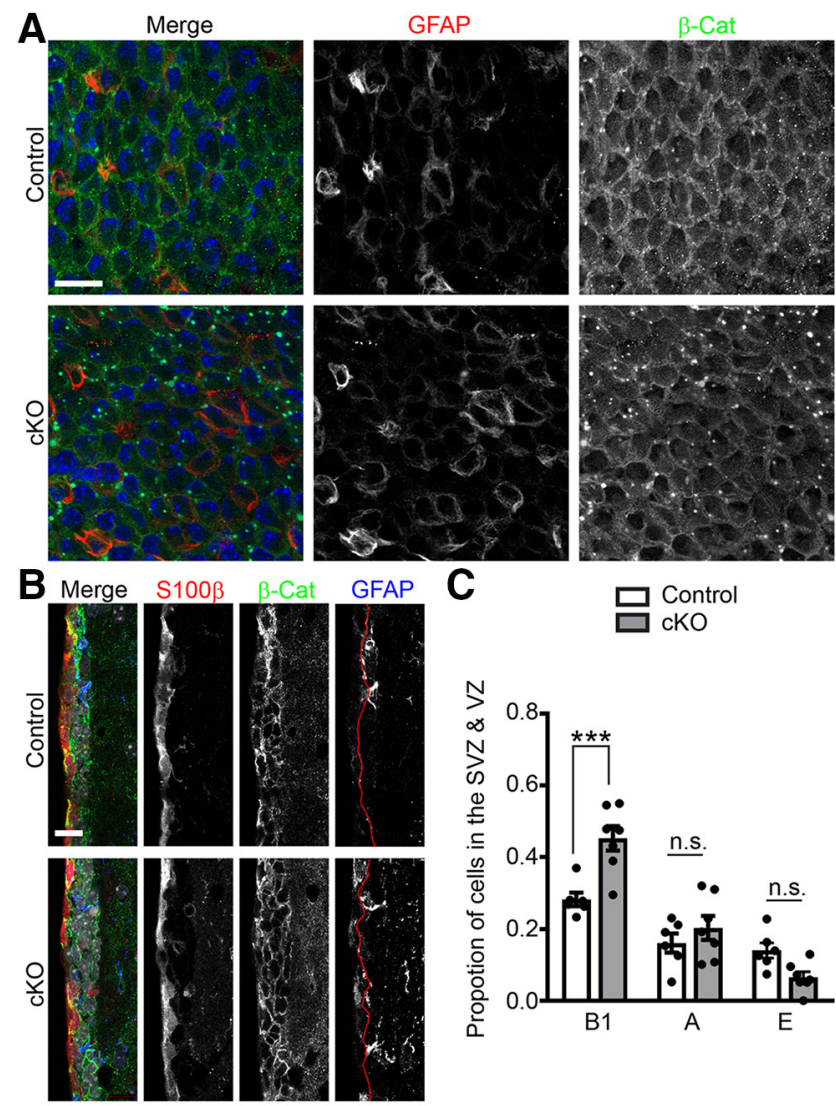

Figure 2. Loss of Cyfip 1 alters the structure of the ventricular surface in adult Cyfip 1 CKO mice. $A$, Sample confocal images of the ventricular surface in control and Cyfip $1 \mathrm{CKO}$ adult mice. Whole-mount preparations were immunostained for $\beta$-catenin (green), GFAP (red), and DAPI (blue in merged image). Scale bar, $20 \mu \mathrm{m}$. B, Sample confocal images of coronal sections of the lateral ventricle of the adult SVZ in control versus CKO animals. Sections immunostained with antibodies targeting $S 100 \beta$ (red), $\beta$-catenin (green), and GFAP (blue). Red line indicates the border between the first cell layer at the ventricular surface and the SVZ. Scale bar, $10 \mu \mathrm{m}$. $C$, Quantification of the cellular composition of the SVZ and ventricular surface. The number of $\mathrm{GFAP}^{+}$and $\mathrm{S} 100 \beta^{+}$cells were quantified in relation to the total number of cells based on nuclear DAPI staining. B1, GFAP ${ }^{+}$S100 $\beta^{-}$Type B1 cells; $\mathrm{A}_{\mathrm{GFAP}}{ }^{+} \mathrm{S} 100 \beta^{+}$astrocytes; $\mathrm{E}$, $\mathrm{GFAP}^{-} \mathrm{S} 100 \beta^{+}$ependymal cells. Each dot represents the mean counts of three sections per animal. Bars indicate mean \pm SEM; $n=6$ control and 7 cKO animals. One-way ANOVA followed by Sidak's multiple-comparisons test: ${ }^{* *} p<0.001 ;$ n.s., not significant, $p>0.05$.

sion is driven by the Nestin promoter that becomes active in NSCs and neural progenitor cells during embryonic brain development (Giusti et al., 2014).

Examination of the lateral ventricular surface of the NestinCre:Cyfip $1^{\mathrm{f} / \mathrm{f}} \mathrm{cKO}$ adult animals (cKO) compared with littermate controls (Con) carrying the Cyfip $1^{\mathrm{f} / \mathrm{f}}$ alleles, but not expressing Cre, reveals significant changes in the cellular organization at the ventricular surface (Fig. $2 A$ ). In whole-mount sections, there appears to be an increase in the number of $\mathrm{GFAP}^{+}$cell bodies at the ventricular surface of the $\mathrm{cKO}$ animals compared with the controls. Additionally, compared with the control SVZ, where there is prominent GFAP immunoreactivity in the apical processes of B1 cells, the ventricular-projecting processes are not as clearly demarcated in the cKO SVZ. There is also a change in $\beta$-catenin expression at the ventricular surface with less uniform immunostaining at cell-cell junctions (Fig. 2A).

We next examined coronal sections of control and $\mathrm{cKO}$ adult animals to more clearly define changes in the cellular composition and organization observed in the whole-mount preparations. Immunostaining with antibodies directed toward GFAP, 
A
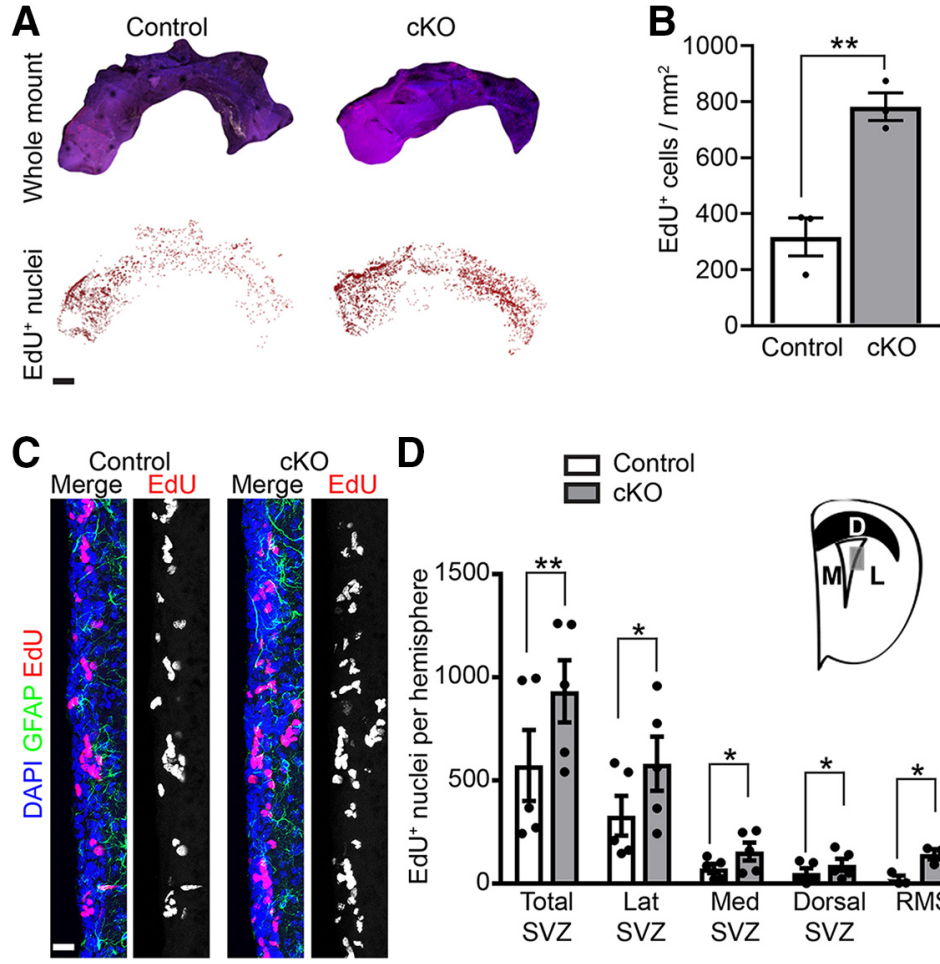

Figure 3. Loss of Cyfip1 during embryonic development results in altered cell proliferation in the adult SVZ. A, Sample images of whole-mount preparations of EdU-injected control and cKO adult mice $24 \mathrm{~h}$ after injection. Tiled 3D images were obtained to capture the entire ventricular surface and reconstructed in Imaris software. EdU ${ }^{+}$nuclei were marked for quantification (red dots). Scale bar, $500 \mu \mathrm{m} . \boldsymbol{B}, \mathrm{EdU}^{+}$cells as in $\boldsymbol{A}$ were quantified and normalized to the total area of the ventricular surface for each animal as shown as individual dots. Bars indicate mean $\pm \mathrm{SEM} ; n=3$ animals for each condition. ${ }^{* *} p<0.001$ (paired two-tailed $t$ test). C, Sample confocal images of the lateral wall of the lateral ventricles in coronal section from control and cK0 animals stained with EdU (red), GFAP (green), and DAPI (blue). Images are orthogonal reconstructions of a subarea of the ventricular wall similar to the gray box in $\boldsymbol{D}$ (inset). Scale bar, $20 \mu \mathrm{m}$. $\boldsymbol{D}$, Quantification of EdU ${ }^{+}$cells in $40 \mu \mathrm{m}$ coronal sections. Every sixth section beginning from the posterior frontal lobe just anterior to the ventricle (RMS) and extending to the dentate gyrus of the hippocampus was examined. Each dot represents the value of the total cells quantified for each animal, with a minimum of 7 sections along the anterior to posterior axis of the lateral ventricles examined with variation dependent on the size of the ventricle and no difference in number of sections between genotypes. Bars indicate mean \pm SEM; $n=5$ animals for control and 5 animals for cKO, except $n=3$ animals for RMS Paired two-tailed $t$ test: ${ }^{* *} p<0.005 ;{ }^{*} p<0.05$.

$S 100 \beta$, and $\beta$-catenin demonstrates an increase in the number of $\mathrm{GFAP}^{+}$cell bodies of Type B1 NSCs in the SVZ and at the ventricular surface (Fig. 2B). In the control animals, the majority of cells along the ventricular surface are $\mathrm{S} 100 \beta^{+} \mathrm{GFAP}^{-}$ependymal cells, whereas $\mathrm{GFAP}^{+} \mathrm{B} 1$ cells and astrocytes typically lie below the surface in the SVZ (Fig. $2 B$ ). In the cKO animals, there is a marked increase in $\mathrm{GFAP}^{+}$cells at the surface (Fig. $2 B$, bottom, left of red line). Additionally, when the numbers of each cell type are quantified in proportion to the total number of cells in the $\mathrm{SVZ}$ and at the VZ, the relative proportion of $\mathrm{GFAP}^{+} \mathrm{S} 100 \beta^{-}$ Type $\mathrm{B} 1$ cells is increased in the cKO animals compared with the controls. There is no difference in the number of GFAP ${ }^{+} \mathrm{S} 100 \beta^{+}$ astrocytes and $\mathrm{GFAP}^{-} \mathrm{S} 100 \beta^{+}$ependymal cells (B1 Control vs cKO mean difference $=-0.17,95 \% \mathrm{CI}[-0.265,-0.7526], p<$ 0.005 ; $\mathrm{E}$ Control vs $\mathrm{cKO}$ mean difference $=0.075,95 \% \mathrm{CI}$ $[-0.020,0.017], p=0.159 ;$ A Control vs $\mathrm{cKO}$ mean difference $=$ $0.042,95 \%$ CI $[-0.034,0.052], p=0.609 ; n=5$ animals per condition; one-way ANOVA followed by Sidak's multiplecomparisons test; Fig. 2C). These data demonstrate a change in the cellular composition of the SVZ and ventricular surface. The increase in the number of B1 cells at the surface suggests either a translocation of cells to the ventricular surface from beneath, an expansion of the population of cells at the surface, or both.
Loss of Cyfip1 increases proliferating cells at the ventricular surface of adult animals

We hypothesized that the increase in $\mathrm{GFAP}^{+} \mathrm{B} 1$ cells at the ventricular surface is the result of the GFAP ${ }^{+}$NSCs translocating to the ventricular surface and dividing there. To test this hypothesis, we performed EdU incorporation experiments to label actively cycling cells in the $S$ phase. We injected 56- to 70-d-old control animals as well as littermate $\mathrm{cKO}$ animals with a single intraperitoneal dose of $200 \mathrm{mg} / \mathrm{kg}$ body weight of EdU. After $24 \mathrm{~h}$, whole-mount and coronal sections were used for immunostaining, EdU labeling, and quantification. In the whole-mount preparations, there is a significant increase in the number of $\mathrm{EdU}^{+}$nuclei at the ventricular surface in the $\mathrm{cKO}$ animals compared with controls (Con $=316 \pm 67$ cells $/ \mathrm{mm}^{2}, n=3$ animals vs $\mathrm{cKO}=782 \pm$ 49 cells $/ \mathrm{mm}^{2}, n=3$ animals; $p<0.05$; unpaired $t$ test; Fig. $3 A, B$ ), indicating an increase in proliferation of cells at or near the ventricular surface.

As the whole-mount preparations only allow visualization of the lateral wall of the lateral ventricle, we also examined coronal preparations of 56- to 70-d-old animals at $24 \mathrm{~h}$ after EdU injection. The number of $\mathrm{EdU}^{+}$cells at the ventricular surface and in the SVZ was quantified by counting the total number of $\mathrm{EdU}^{+}$cells lining the lateral wall, the medial wall, and the dorsal wall of the ventricle in every sixth $40 \mu \mathrm{m}$ coronal section from the first section containing the anterior SVZ to the posterior SVZ at the level of the dentate gyrus for each animal (Fig. $3 C, D$ ). As in the whole-mount preparations, there is an increase in $\mathrm{EdU}^{+}$cells in the $\mathrm{cKO}$ animals compared with the controls (total cKO vs Con mean of differences $=360 \pm 62.1$ cells per hemisphere; $n=5$ animals, $p<0.005$; paired two-tailed $t$ test; Fig. 3D). This increase is reflective of significant increases in proliferating cells independently in the lateral wall (Lateral cKO vs Con mean of difference $=252 \pm 69.9$ cells per hemisphere; $n=5$ animals, $p<0.05$; two-tailed paired $t$ test), the dorsal wall (Dorsal cKO vs Con mean of difference $=39.8 \pm 12.72$ cells per hemisphere; $n=5$ animals, $p<0.05$; paired two-tailed $t$ test), and the medial wall (Medial cKO vs Con mean of difference $=81.8 \pm 26.42$ cells per hemisphere; $n=5$ animals, $p<$ 0.05 ; paired two-tailed $t$ test) (Fig. $3 D$ ). The number of $\mathrm{EdU}^{+}$ cells in the rostral migratory stream (RMS) just anterior to the ventricles was also independently quantified and shows an increase in the cKO animals (RMS cKO vs Con mean of difference $=121.3 \pm 23.35$ cells per hemisphere; $n=3$ animals, $p<0.05$; paired two-tailed $t$ test; Fig. $3 D$ ). This increase in the number of EdU ${ }^{+}$cells entering the proximal RMS supports an increase in the generation of new cells rather than a failure to migrate from the ventricular surface. 

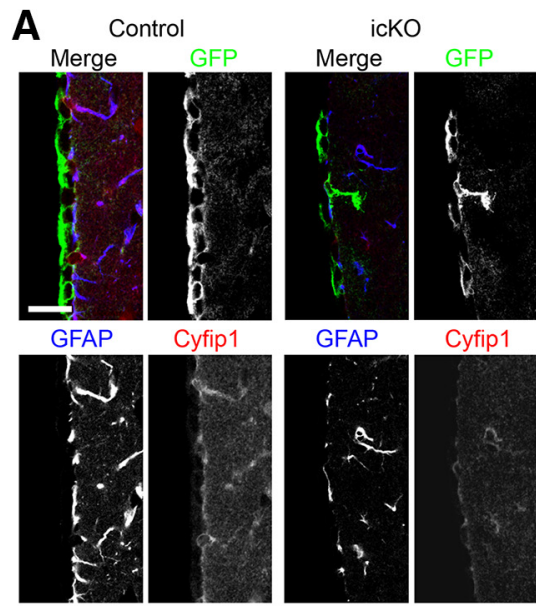

B
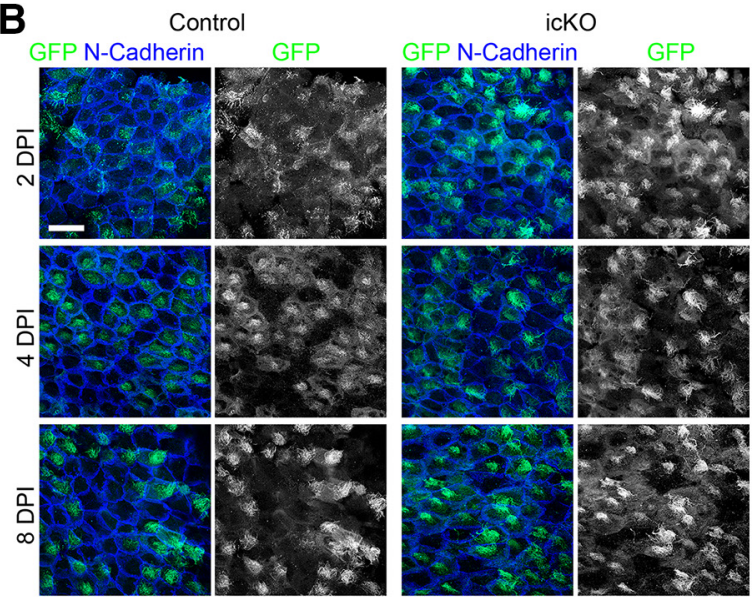

Figure 4. Acute deletion of Cyfip1 in the adult SVZ. A, Sample confocal images of the ventricular wall of control and icK0 adult animals demonstrating decreased Cyfip1 levels by immunofluorescence. Scale bar, $20 \mu \mathrm{m}$. B, Sample confocal images of N-cadherin (blue) and GFP (green) immunofluorescence at 2, 4, and $8 \mathrm{dpi}$ in whole-mount preparations in control and ick0 mice. Scale bar, $20 \mu \mathrm{m}$.

\section{Acute loss of Cyfip1 in the adult SVZ disrupts niche architecture and alters NSC proliferation}

Studies up to this point have examined the effect of loss of $C y$ fip 1 during embryonic development and therefore cannot distinguish between the downstream effects of altering the embryonic neurogenic niche or a persistent need for Cyfip1 in the adult niche. To determine whether Cyfip1 plays a persistent functional role in the adult neurogenic niche, we developed an inducible cKO animal (icKO) to delete the Cyfip1 gene specifically in the NSCs in the SVZ of adult animals after the niche is already established. We used a tamoxifen-inducible Cre-lox system in which expression of a Cre recombinase protein with an estrogen receptor motif (Cre-ER) is driven by the Nestin promoter (Balordi and Fishell, 2007). To verify Cre expression and to label cells in which recombination occurred, Nestin-CreER animals were crossed with the $m T m G$ reporter mouse (Muzumdar et al., 2007).

Adult control animals containing the Nestin-CreER:Cyfip ${ }^{+/+}$: $m T m G$ transgenes that were WT for Cyfip1 (Control) as well as animals with a Nestin-CreER:Cyfip ${ }^{\mathrm{f} / \mathrm{f}}: m T m G$ genotype (icKO) were injected with tamoxifen between P56 and P84. Animals were then sacrificed at 2, 4, and 8 days post injection (dpi) for analysis. Animals killed at 8 dpi demonstrated decreased levels of Cyfip1 protein in the $\mathrm{GFAP}^{+}$cells beneath the cell surface (Fig. $4 A$ ). Quantification of the relative immunofluorescence levels for $\mathrm{Cy}$ fip1 showed $\sim 45 \%$ of controls in icKO animals (mean Cyfip1 immunofluorescence intensity $49.5 \pm 5.5$ intensity units, $n=5$ Control cells vs $22.2 \pm 4.1$ intensity units, $n=13$ icKO cells; $p=$ 0.002 ; unpaired $t$ test). Whole-mount immunostaining with antibodies targeted against GFP, marking recombined $\mathrm{mTmG}^{+}$ cells, indicates that, as early as $2 \mathrm{dpi}$, Cre-mediated recombination occurs at similar frequencies in both the control and icKO animals. There is an increase in the intensity of GFP immunofluorescence by 4 and $8 \mathrm{dpi}$ in both conditions (Fig. $4 B$ ).

To determine whether Cyfip1 is required for regulation of the SVZ niche, we examined GFAP expression as well as N-cadherin expression at the ventricular surface after tamoxifen induction. At $8 \mathrm{dpi}$, there is a marked increase in the number of $\mathrm{GFAP}^{+}$cells at the ventricular surface (Fig. 5A,B). This increase in GFAP immunoreactivity occurs in the form of an increased number of apical process clusters as well as an increased number of cell bodies at the cell surface and is reflective of a significant increase in the number of normal and abnormal pinwheel formations
(icKO vs Con mean of differences $=7.95 \pm 1.37 \mathrm{GFAP}^{+}$cells/ $100 \mathrm{~mm}^{2}, p<0.05$, paired two-tailed $t$ test; Fig. 5B). When the expression of $\mathrm{N}$-cadherin and GFAP in the pinwheel formations is examined at a high magnification in the control SVZ, there is a distinct demarcation between the $\mathrm{GFAP}^{+}$apical projections and the ependymal cells at the surface with very little overlap between GFAP and N-cadherin immunostaining, and intense $\mathrm{N}$-cadherin immunostaining surrounding the central apical projections (Fig. $5 C$, control, arrowheads). In contrast, there is a marked overlap in $\mathrm{N}$-cadherin and GFAP expression in the iCKO animals at $8 \mathrm{dpi}$. In the absence of Cyfip1, N-cadherin is no longer excluded from the center of the apical projection, and there is no longer a clear demarcation between B1 cells and non-GFAP-expressing cells at the surface (Fig. 5C, 8 dpi, arrowheads). Additionally, cell-cell junctions along the surface are thicker and less clearly defined compared with the controls. At 2 and $4 \mathrm{dpi}$, some of the GFAP ${ }^{+}$ projections of the icKO animals are similar to the control animals. In others, the phenotype is similar to the $\mathrm{GFAP}^{+}$processes of the 8 dpi icKO animals (Fig. 5 C). These results indicate that the structural changes begin before the 8 dpi time point.

We further examined the effect of acute Cyfip 1 deletion on the cellular distribution of the SVZ niche in coronal sections from tamoxifen-injected mice at $8 \mathrm{dpi}$. Cells were immunostained for GFP, GFAP, and S100 $\beta$ to determine the relative number of $\mathrm{GFAP}^{+}$S100 $\beta^{-} \mathrm{B} 1$ cells, $\mathrm{GFAP}^{-} \mathrm{S} 100 \beta^{+}$ependymal cells, and $\mathrm{GFAP}^{+} \mathrm{S} 100 \beta^{+}$astrocytes compared with the total $\mathrm{GFP}^{+}$recombined cells at the ventricular surface and in the SVZ (Fig. 6A). Similar to the cKO animals in which Cyfip1 is deleted from the embryonic NSCs, there is a significant increase in the number of $\mathrm{GFAP}^{+} \mathrm{S} 100 \beta^{-} \mathrm{B} 1$ cells relative to total cells in the icKO animals compared with controls (B1 Con vs icKO mean difference $=$ $-0.121,95 \%$ CI $[-0.235,-0.008], n=7$ animals per condition, $p<0.05$; one-way ANOVA followed by Sidak's multiplecomparisons test; Fig. $6 \mathrm{~B}$ ). There was not a significant change in either the number of ependymal cells or astrocytes (E Con vs icKO mean difference $=0.03552,95 \%$ CI $[-0.078,0.148], p=$ 0.821; A Con vs icKO mean difference $=-0.017,95 \% \mathrm{CI}$ $[-0.130,0.096], p=0.976 ; n=7$ animals per condition; one-way ANOVA followed by Sidak's multiple-comparisons test; Fig. 6B). These results suggest that Cyfip1 specifically regulates the number of GFAP ${ }^{+}$S100 $\beta^{-}$B1 cells at the ventricular surface and in the SVZ. 

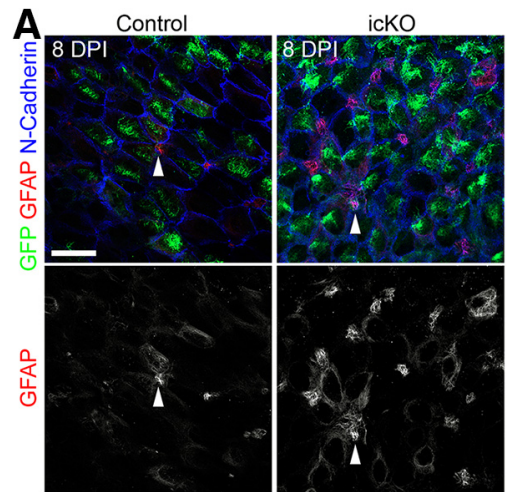

B
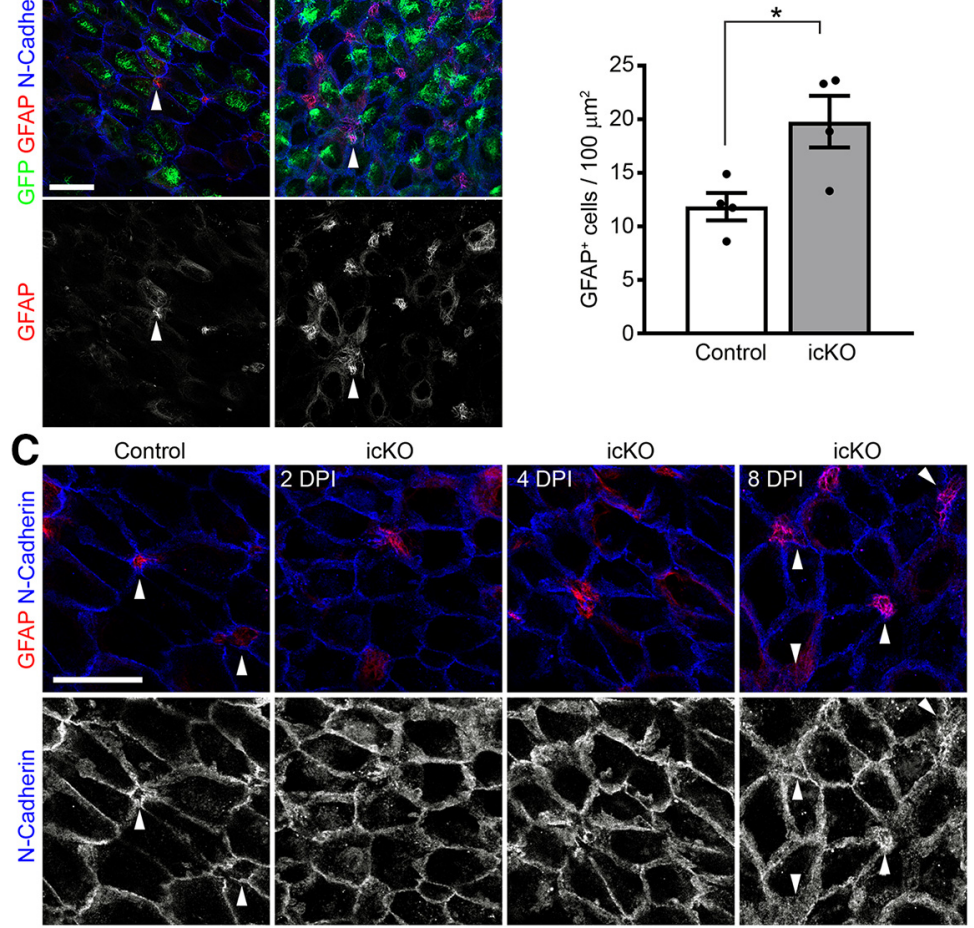

Figure 5. Acute loss of (yfip 1 disrupts the adult ventricular surface. $A$, Sample confocal images of whole-mount preparations from control and icK0 adult animals at 8 dpi that are immunostained for GFP (green), GFAP (red), and N-cadherin (blue). Arrowheads indicate $\mathrm{GFAP}^{+}$apical processes at the surface. Scale bar, $20 \mu \mathrm{m}$. B, Quantification of the number of GFAP ${ }^{+}$cell contacts at the cell surface of whole-mount preparations. Each dot represents the value from each animal. Bars indicate mean $\pm S E M ; n=$ 4 animals per condition. ${ }^{*} p<0.05$ (two-tailed paired $t$ test). C, Sample confocal high-magnification images of whole-mount preparations immunostained for GFAP (red) and N-cadherin (blue). Arrowheads indicate Type B1 cells and ependymal junctions in control versus cK0 animals at 2, 4, and 8 dpi. Scale bar, $20 \mu \mathrm{m}$.

A

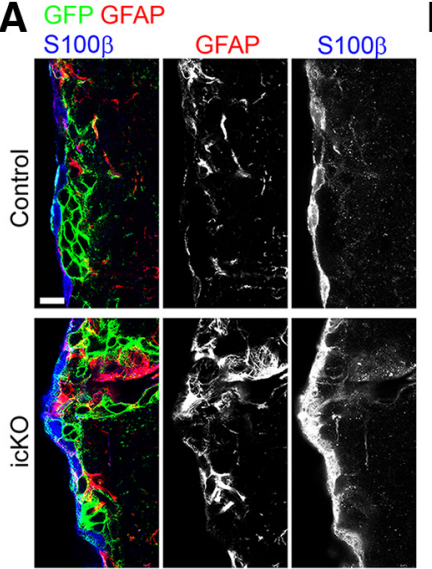

B

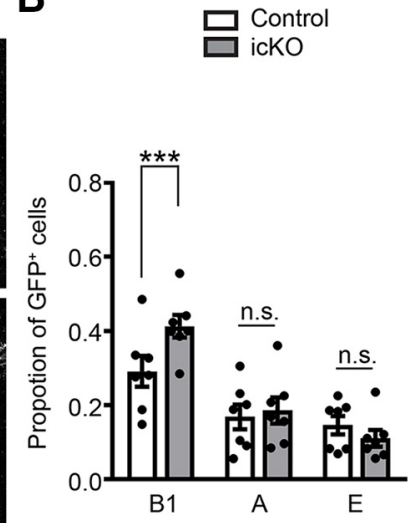

Figure 6. Acute loss of Cyfip 1 increases the proportion of $\mathrm{GFAP}^{+} \mathrm{B} 1$ cells in the adult SVZ.A, Sample confocal images of coronal sections immunostained for GFAP (red), GFP (green), and S100 $\beta$ (blue) from control and icK0 adult animals. Scale bar, $10 \mu \mathrm{m}$. $\boldsymbol{B}$, Quantification of GFAP ${ }^{+} s 100 \beta^{-}$cells (B1), GFAP ${ }^{+} s 100 \beta^{+}$astrocytes (A), and GFAP ${ }^{-}$s $100 \beta^{+}$ependymal cells (E) expressing GFP compared with the total GFP ${ }^{+}$cells at the ventricular surface and in the SVZ of the lateral wall of the lateral ventricles. Each dot represents the mean of three sections per animal. Bars indicate mean \pm SEM; $n=7$ animals per condition. One-way ANOVA followed by Sidak's multiple-comparisons test: ${ }^{* * *} p<0.001 ;$ n.S., not significant, $p>0.05$.

To determine whether there is an increase in the proliferation of B1 cells within the niche, we injected P56-P84 control and icKO animals with tamoxifen, followed by injection with EdU at $2 \mathrm{~h}$ before perfusion at $8 \mathrm{dpi}$. Coronal sections were subsequently immunostained with antibodies against Sox2, a transcription factor expressed in B1 cells, and GFP (Fig. 7A). Consistent with the results of $\mathrm{GFAP}^{+} \mathrm{B} 1$ cell quantification, there was a proportional increase in the number of Sox $2^{+} \mathrm{GFP}^{+}$cells relative to all $\mathrm{GFP}^{+}$cells in the icKO animals compared with the controls (Con vs icKO mean difference $=-0.192,95 \% \mathrm{CI}$ $[-0.289,-0.094], n=4$ animals per condition, $p<0.001$; one-way ANOVA followed by Sidak's multiple-comparisons test; Fig. $7 B$ ). Additionally, there was an increase in the number of Sox $2^{+} \mathrm{GFP}^{+}$ $\mathrm{EdU}^{+}$cells in the icKO compared with control animals (Con vs icKO mean difference $=-0.147,95 \%$ CI $[-0.227$, $-0.003], n=3$ animals per condition, $p<0.05$; one-way ANOVA followed by Sidak's multiple-comparisons test; Fig. $7 B)$. These results indicate that there are more Sox $2^{+}$B1 cells, and they exhibit a higher rate of proliferation upon Cyfip1 deletion.

Previous studies have shown that B1 cell division in the SVZ leads to either a symmetric expansion of $B 1$ cells or to neurogenic cell divisions (Obernier et al., 2018). To assess whether the increased divisions that occur in the absence of Cyfip 1 are self-renewing or neurogenic, or a combination of both, 8 dpi coronal sections from control and icKO animals were immunostained for Mash1, a transcription factor expressed in transient amplifying cells (Fig. $7 C$ ), and Dcx, a microtubule-associated protein expressed in neuroblasts (Fig. 7D). In contrast to the Sox $2^{+}$cells, there was no significant change in the proportion of Mash1 ${ }^{+}$ transient amplifying cells among $\mathrm{GFP}^{+}$cells in the icKO compared with the controls (Con $=0.103 \pm 0.025, n=6$ animals; icKO $=0.117 \pm 0.009, n=8$ animals; $p=0.5$, two-tailed $t$ test; Fig. $7 E$, left). Similarly, there was no difference between the proportion of $\mathrm{Dcx}^{+} \mathrm{GFP}^{+}$neuroblasts among $\mathrm{GFP}^{+}$cells in control and icKO animals (Con $=0.297 \pm 0.011, n=7$ animals; icKO $=$ $0.312 \pm 0.019, n=8$ animals; $p=0.5$, two-tailed $t$ test; Fig. $7 E$, right). Together, these data indicate that acute loss of Cyfip 1 does not lead to an increase in cells with a neurogenic fate, and support the hypothesis that the increased B1 cell divisions upon Cyfip 1 deletion are symmetric self-renewing.

\section{Discussion}

In this study, we demonstrate that Cyfip1 is important for proper establishment and maintenance of the adult SVZ niche architecture and regulation of Type $\mathrm{B} 1$ cell proliferation and localization. While the importance of Cyfip1 in embryonic development and mature neuronal plasticity is beginning to be appreciated (De Rubeis et al., 2013; Abekhoukh and Bardoni, 2014; Yoon et al., 2014; Abekhoukh et al., 2017), this study is the first to suggest that Cyfip1 is a critical component in establishing and maintaining the adult SVZ NSC niche and regulating adult NSC fate. Our study further suggests that Type B1 adult NSCs maintain the capacity for symmetric self-renewal to amplify their pool in the adult brain. 
In contrast to the embryonic period, where there is prominent Cyfip1 expression in the apical membranes of RGCs covering the entire ventricular surface (Yoon et al., 2014), our study demonstrates that the overall expression of $\mathrm{Cy}$ fip 1 at the ventricular surface decreases in the adult SVZ as RGCs differentiate into ependymal cells. Remarkably, this indicates an expression specificity for NSCs as Cyfip1 continues to be expressed in the $\mathrm{GFAP}^{+}$Type B1 NSCs and is not prominent in the $\mathrm{S} 100 \beta^{+} \mathrm{GFAP}^{-}$mature ependymal cells. Similar to what is seen in the RGCs of embryonic development, there is specific localization of this protein to the apical processes at the ventricular surface in the adult SVZ and overlap with $\mathrm{N}$-cadherin expression at cell-cell junctions. As is the case in embryonic development, Cyfip1 is involved in the regulation of adherens junctions in the adult SVZ and is required for NSC niche maintenance.

Mirzadeh et al. (2008) have previously shown by electron microscopy that adherens junctions in the pinwheel formations of the adult SVZ are asymmetric between ependymal cells and Type B1 cells. Junctions between $\mathrm{B} 1$ cells are similar to those seen between RGCs in development. Ependymal-ependymal cell junctions are different from both (Mirzadeh et al., 2008). Asymmetric persistence of Cyfip1 expression and the resultant differential regulation of adherens junctions in B1 cells, but not in ependymal cells, is one potential mechanism leading to B1 cell-specific adherens junctions. In support of this notion, in the control SVZ, there is a discrete localization of $\mathrm{N}$-cadherin to the cell-cell junctions in $\mathrm{B} 1$ cells. Acute deletion of Cyfip1 results in a dispersion of $\mathrm{N}$-cadherin from a discrete apical membrane ring surrounding $\mathrm{GFAP}^{+}$processes, suggesting that Cyfip1 stabilizes $\mathrm{N}$-cadherin at the apical cell-cell junction.

In the embryonic NSC niche, disrupted adherens junction stability leads to shorter cell cycles and a reduction of cells that exit the cell cycle (Gil-Sanz et al., 2014). Here, we observed an increase in cell division as well as an increase in the number of B1 cells in the adult SVZ as a consequence of loss of Cyfip 1 during the embryonic stages. Previous work has demonstrated that B1 cell divisions in the adult SVZ are either symmetrically self-depleting or symmetrically self-renewing, and the balance between the two favors depletion over time, leading to a progressive decrease in B1 cells with aging (Obernier et al., 2018). An increase in cell divisions can either lead to depletion or expansion of the overall NSC pool depending on which type of division is enhanced. In another model examining niche regulation of $\mathrm{B} 1$ cell division in the adult SVZ, loss of apical end feet anchoring in the niche by blocking vascular molecular adhesion molecule-1 leads to disrupted pinwheel architecture and increased self-depleting neurogenic divisions with a resultant depletion of B1 cells (Kokovay et al., 2012). In contrast, in this study, we found increased self-renewing proliferation and a specific expansion of B1 cells upon Cyfip1 deletion.

In the cKO model, it is possible that loss of Cyfipl during embryonic development alters the structure of the niche; and it is the dysregulated niche, but not a persistent need for Cyfip 1 in the adult niche, that contributes to the observed effects. However, the marked loss of localization of N-cadherin to cell-cell junctions, accompanied by the expansion of Type B1 cells and an increase in their proliferation when Cyfipl is acutely depleted in our icKO model, indicates that persistent Cyfip 1 expression in $\mathrm{B} 1$ cells is indeed required to maintain the niche. Furthermore, the upregulation of self-renewing proliferation after acute deletion of Cyfip 1 without an increase in transient amplifying cells or neuroblasts indicates that there is not an immediate increase in neurogenesis as a result of the acute loss of Cyfip1. This result suggests that it is possible to attenuate or reverse the progressive depletion of B1 cells in the adult SVZ of control animals and that normal levels of Cyfip1 protein expression are required to regulate fate choices and maintain the balance between renewing and depleting neurogenic divisions of $\mathrm{B} 1$ cells.

The exact mechanisms by which Cyfip1 regulates these processes are unclear. It is possible that the symmetric versus asymmetric adherens junctions provide information to B1 cells about the surrounding cells and the loss of adhesion acts as a signal to B1 cells to generate new cells through division. Alternatively, Cyfip1 may regulate cell fate choice through a signaling mechanism in- 
dependent of its role in adherens junction maintenance; further studies are needed to elucidate which of these hypotheses is correct. In contrast to the acute ickO model in which there is no increase in neuroblasts, when Cyfipl is lost during the embryonic stage in the cKO model, there is an increase in cycling cells in the RMS. We hypothesize that Cyfip1 KO in neural progenitor cells during embryonic development would lead to subsequent early expansion of the B1 cell population. Because Cyfip1 KO does not completely stop neurogenic divisions, there are more B1 cells later in the adult SVZ that are available to generate new neurons, which would potentially lead to an increase in the number of cells in the RMS. Understanding the regulation of this later fate determination will be important to understanding both normal and pathologic development.

The potential of $\mathrm{B} 1$ cells in the adult to reactivate their capacity for symmetric self-renewing divisions after embryonic development could have implications for regeneration as well as oncologic transformation. With regards to the latter possibility, it should be noted that CYFIP1 has been proposed as a tumor invasion suppressor in humans (J. M. Silva et al., 2009). Additionally, the phenotype observed in our cKO model demonstrating increased symmetric renewing divisions in the adult after embryonic deletion is pertinent to recent findings demonstrating that humans who are haploinsufficient for CYFIP1 due to deletion of the 15q11.2 locus, where the gene is located, have microstructural alterations in the white matter as detected by MRI (A. I. Silva et al., 2019a). Additionally, mice that are haploinsufficient for Cyfip1 have decreased myelination in the corpus callosum and decreased numbers of oligodendrocytes and abnormal behavior (Domínguez-Iturza et al., 2019; A. I. Silva et al., 2019b). Although there are many hypotheses as to why loss of Cyfip1 in mice could alter myelination based on its known role in actin nucleation, which is necessary for migration and adhesion, the data presented here suggest the possibility that the increased symmetric B1 cell-renewing divisions could occur at the expense of the generation of oligodendrocytes, resulting in impaired myelination either in the prenatal or postnatal period or both.

CYFIP1 is located within the 15q11.2 locus in humans, and deletions or duplications in this region are found in patients with epilepsy, intellectual disability, autism, and schizophrenia (Doornbos et al., 2009; Mefford et al., 2010; de Kovel et al., 2010; van der Zwaag et al., 2010; von der Lippe et al., 2011; Mullen et al., 2013; Rudd et al., 2014; Borlot et al., 2017). Copy number variation in the 15q11.2 locus also results in changes in white matter microstructure (A. I. Silva et al., 2019a). The role of Cyfip1 as a member of the WAVE regulatory complex in regulating actin nucleation makes it an ideal candidate to regulate synaptic plasticity as well as early neural development (De Rubeis et al., 2013; Yoon et al., 2014; Abekhoukh et al., 2017). Results presented here suggest that it continues to be important in postnatal NSC regulation with potentially important downstream effects on postnatal neuron and oligodendrocyte genesis. Building on the previous finding of the necessity of Cyfip 1 for the establishment of apical basal polarity in embryonic neurogenesis (Yoon et al., 2014), this study reveals a persistent requirement for its expression in the adult neurogenic niche. Together, these results indicate that Cyfip1 is crucial to NSC behavior and the neurogenic niche throughout life. Importantly, we show that Cyfip1 suppresses self-renewing B1 cell divisions and that NSCs can be reactivated to favor selfrenewal, even in the adult SVZ.

\section{References}

Abekhoukh S, Bardoni B (2014) CYFIP family proteins between autism and intellectual disability: links with fragile X syndrome. Front Cell Neurosci $8: 81$.

Abekhoukh S, Sahin HB, Grossi M, Zongaro S, Maurin T, Madrigal I, KazueSugioka D, Raas-Rothschild A, Doulazmi M, Carrera P, Stachon A, Scherer S, Drula Do Nascimento MR, Trembleau A, Arroyo I, Szatmari P, Smith IM, Milà M, Smith AC, Giangrande A, et al. (2017) New insights into the regulatory function of CYFIP1 in the context of WAVE- and FMRP-containing complexes. Dis Model Mech 10:463-474.

Altman J (1969) Autoradiographic and histological studies of postnatal neurogenesis: IV. Cell proliferation and migration in the anterior forebrain, with special reference to persisting neurogenesis in the olfactory bulb. J Comp Neurol 137:433-457.

Alvarez-Buylla A, Lim DA (2004) For the long run: maintaining germinal niches in the adult brain. Neuron 41:683-686.

Balordi F, Fishell G (2007) Mosaic removal of hedgehog signaling in the adult SVZ reveals that the residual wild-type stem cells have a limited capacity for self-renewal. J Neurosci 27:14248-14259.

Berg DA, Su Y, Jiménez-Cyrus D, Patel A, Huang N, Morizet D, Lee S, Shah R, Ringeling FR, Jain R, Epstein JA, Wu QF, Canzar S, Ming GL, Song H, Bond AM (2019) A common embryonic origin of stem cells drives developmental and adult neurogenesis. Cell 177:654-668.e15.

Bizzotto S, Francis F (2015) Morphological and functional aspects of progenitors perturbed in cortical malformations. Front Cell Neurosci 9:30.

Bond AM, Ming GL, Song H (2015) Adult mammalian neural stem cells and neurogenesis: five decades later. Cell Stem Cell 17:385-395.

Borlot F, Regan BM, Bassett AS, Stavropoulos DJ, Andrade DM (2017) Prevalence of pathogenic copy number variation in adults with pediatriconset epilepsy and intellectual disability. JAMA Neurol 74:1301-1311.

de Kovel CG, Trucks H, Helbig I, Mefford HC, Baker C, Leu C, Kluck C, Muhle H, von Spiczak S, Ostertag P, Obermeier T, Kleefuss-Lie AA, Hallmann K, Steffens M, Gaus V, Klein KM, Hamer HM, Rosenow F, Brilstra EH, Trenité DK, et al. (2010) Recurrent microdeletions at 15q11.2 and 16 p13.11 predispose to idiopathic generalized epilepsies. Brain 133:2332.

De Rubeis S, Pasciuto E, Li KW, Fernández E, Di Marino D, Buzzi A, Ostroff LE, Klann E, Zwartkruis FJ, Komiyama NH, Grant SG, Poujol C, Choquet D, Achsel T, Posthuma D, Smit AB, Bagni C (2013) CYFIP1 coordinates mRNA translation and cytoskeleton remodeling to ensure proper dendritic spine formation. Neuron 79:1169-1182.

Doetsch F, Caillé I, Lim DA, García-Verdugo JM, Alvarez-Buylla A (1999) Subventricular zone astrocytes are neural stem cells in the adult mammalian brain. Cell 97:703-716.

Domínguez-Iturza N, Lo AC, Shah D, Armendáriz M, Vannelli A, Mercaldo V, Trusel M, Li KW, Gastaldo D, Santos AR, Callaerts-Vegh Z, D’Hooge R, Mameli M, Van der Linden A, Smit AB, Achsel T, Bagni C (2019) The autism- and schizophrenia-associated protein CYFIP1 regulates bilateral brain connectivity and behaviour. Nat Commun 10:3454.

Doornbos M, Sikkema-Raddatz B, Ruijvenkamp CA, Dijkhuizen T, Bijlsma EK, Gijsbers AC, Hilhorst-Hofstee Y, Hordijk R, Verbruggen KT, Kerstjens-Frederikse WS, van Essen T, Kok K, van Silfhout AT, Breuning M, van Ravenswaaij-Arts CM (2009) Nine patients with a microdeletion 15q11.2 between breakpoints 1 and 2 of the Prader-Willi critical region, possibly associated with behavioural disturbances. Eur J Med Genet 52: $108-115$.

Ferland RJ, Batiz LF, Neal J, Lian G, Bundock E, Lu J, Hsiao YC, Diamond R, Mei D, Banham AH, Brown PJ, Vanderburg CR, Joseph J, Hecht JL, Folkerth R, Guerrini R, Walsh CA, Rodriguez EM, Sheen VL (2009) Disruption of neural progenitors along the ventricular and subventricular zones in periventricular heterotopia. Hum Mol Genet 18:497-516.

Garcia AD, Doan NB, Imura T, Bush TG, Sofroniew MV (2004) GFAPexpressing progenitors are the principal source of constitutive neurogenesis in adult mouse forebrain. Nat Neurosci 7:1233-1241.

Gil-Sanz C, Landeira B, Ramos C, Costa MR, Müller U (2014) Proliferative defects and formation of a double cortex in mice lacking Mltt4 and Cdh2 in the dorsal telencephalon. J Neurosci 34:10475-10487.

Giusti SA, Vercelli CA, Vogl AM, Kolarz AW, Pino NS, Deussing JM, Refojo D (2014) Behavioral phenotyping of Nestin-Cre mice: implications for genetic mouse models of psychiatric disorders. J Psychiatr Res 55:87-95.

Götz M, Huttner WB (2005) The cell biology of neurogenesis. Nat Rev Mol Cell Biol 6:777-788. 
Guerra MM, Henzi R, Ortloff A, Lichtin N, Vío K, Jiménez AJ, DominguezPinos MD, González C, Jara MC, Hinostroza F, Rodríguez S, Jara M, Ortega E, Guerra F, Sival DA, den Dunnen WF, Pérez-Fígares JM, McAllister JP, Johanson CE, Rodríguez EM (2015) Cell junction pathology of neural stem cells is associated with ventricular zone disruption, hydrocephalus, and abnormal neurogenesis. J Neuropathol Exp Neurol 74: 653-671.

Jiménez AJ, García-Verdugo JM, González CA, Bátiz LF, Rodríguez-Pérez LM, Páez P, Soriano-Navarro M, Roales-Buján R, Rivera P, Rodríguez S, Rodríguez EM, Pérez-Fígares JM (2009) Disruption of the neurogenic niche in the subventricular zone of postnatal hydrocephalic hyh mice. J Neuropathol Exp Neurol 68:1006-1020.

Kokovay E, Wang Y, Kusek G, Wurster R, Lederman P, Lowry N, Shen Q, Temple S (2012) VCAM1 is essential to maintain the structure of the SVZ niche and acts as an environmental sensor to regulate SVZ lineage progression. Cell Stem Cell 11:220-230.

Kosodo Y, Röper K, Haubensak W, Marzesco AM, Corbeil D, Huttner WB (2004) Asymmetric distribution of the apical plasma membrane during neurogenic divisions of mammalian neuroepithelial cells. EMBO J 23: $2314-2324$.

Lian G, Sheen VL (2015) Cytoskeletal proteins in cortical development and disease: actin associated proteins in periventricular heterotopia. Front Cell Neurosci 9:99.

Liu P, Jenkins NA, Copeland NG (2003) A highly efficient recombineeringbased method for generating conditional knockout mutations. Genome Res 13:476-484.

Lois C, Alvarez-Buylla A (1993) Proliferating subventricular zone cells in the adult mammalian forebrain can differentiate into neurons and glia. Proc Natl Acad Sci U S A 90:2074-2077.

Lois C, Alvarez-Buylla A (1994) Long-distance neuronal migration in the adult mammalian brain. Science 264:1145-1148.

Mefford HC, Muhle H, Ostertag P, von Spiczak S, Buysse K, Baker C, Franke A, Malafosse A, Genton P, Thomas P, Gurnett CA, Schreiber S, Bassuk AG, Guipponi M, Stephani U, Helbig I, Eichler EE (2010) Genome-wide copy number variation in epilepsy: novel susceptibility loci in idiopathic generalized and focal epilepsies. PLoS Genet 6:e1000962.

Menn B, Garcia-Verdugo JM, Yaschine C, Gonzalez-Perez O, Rowitch D, Alvarez-Buylla A (2006) Origin of oligodendrocytes in the subventricular zone of the adult brain. J Neurosci 26:7907-7918.

Mercier F, Kitasako JT, Hatton GI (2002) Anatomy of the brain neurogenic zones revisited: fractones and the fibroblast/macrophage network. J Comp Neurol 451:170-188.

Mirzadeh Z, Merkle FT, Soriano-Navarro M, Garcia-Verdugo JM, AlvarezBuylla A (2008) Neural stem cells confer unique pinwheel architecture to the ventricular surface in neurogenic regions of the adult brain. Cell Stem Cell 3:265-278.

Mirzadeh Z, Doetsch F, Sawamoto K, Wichterle H, Alvarez-Buylla A (2010) The subventricular zone en-face: wholemount staining and ependymal flow. J Vis Exp 39:1938.

Mullen SA, Carvill GL, Bellows S, Bayly MA, Trucks H, Lal D, Sander T, Berkovic SF, Dibbens LM, Scheffer IE, Mefford HC (2013) Copy number variants are frequent in genetic generalized epilepsy with intellectual disability. Neurology 81:1507-1514.

Muzumdar MD, Tasic B, Miyamichi K, Li L, Luo L (2007) A global doublefluorescent Cre reporter mouse. Genesis 45:593-605.

Obernier K, Cebrian-Silla A, Thomson M, Parraguez JI, Anderson R, Guinto C, Rodas Rodriguez J, Garcia-Verdugo JM, Alvarez-Buylla A (2018) Adult neurogenesis is sustained by symmetric self-renewal and differentiation. Cell Stem Cell 22:221-234.e8.

O'Leary CJ, Nourse CC, Lee NK, White A, Langford M, Sempert K, Cole SJ, Cooper HM (2017) Neogenin recruitment of the WAVE regulatory complex to ependymal and radial progenitor adherens junctions prevents hydrocephalus. Cell Rep 20:370-383.
Parras CM, Galli R, Britz O, Soares S, Galichet C, Battiste J, Johnson JE, Nakafuku M, Vescovi A, Guillemot F (2004) Mash1 specifies neurons and oligodendrocytes in the postnatal brain. EMBO J 23:4495-4505.

Pathania M, Davenport EC, Muir J, Sheehan DF, López-DoménechG, Kittler JT (2014) The autism and schizophrenia associated gene CYFIP1 is critical for the maintenance of dendritic complexity and the stabilization of mature spines. Transl Psychiatry 4:e374.

Priya R, Yap AS (2015) Active tension: the role of cadherin adhesion and signaling in generating junctional contractility. Curr Top Dev Biol 112:65-102.

Relucio J, Menezes MJ, Miyagoe-Suzuki Y, Takeda S, Colognato H (2012) Laminin regulates postnatal oligodendrocyte production by promoting oligodendrocyte progenitor survival in the subventricular zone. Glia 60:1451-1467.

Rousselot P, Lois C, Alvarez-Buylla A (1995) Embryonic (PSA) N-CAM reveals chains of migrating neuroblasts between the lateral ventricle and the olfactory bulb of adult mice. J Comp Neurol 351:51-61.

Rudd DS, Axelsen M, Epping EA, Andreasen NC, Wassink TH (2014) A genome-wide $\mathrm{CNV}$ analysis of schizophrenia reveals a potential role for a multiple-hit model. Am J Med Genet B Neuropsychiatr Genet 165B: $619-626$.

Shook BA, Manz DH, Peters JJ, Kang S, Conover JC (2012) Spatiotemporal changes to the subventricular zone stem cell pool through aging. J Neurosci 32:6947-6956.

Silva AI, Ulfarsson MO, Stefansson H, Gustafsson O, Walters GB, Linden DE, Wilkinson LS, Drakesmith M, Owen MJ, Hall J, Stefansson K (2019a) Reciprocal white matter changes associated with copy number variation at 15q11.2 BP1-BP2: a diffusion tensor imaging study. Biol Psychiatry 85:563-572.

Silva AI, Haddon JE, Ahmed Syed Y, Trent S, Lin TE, Patel Y, Carter J, Haan N, Honey RC, Humby T, Assaf Y, Owen MJ, Linden DE, Hall J, Wilkinson LS (2019b) Cyfip1 haploinsufficient rats show white matter changes, myelin thinning, abnormal oligodendrocytes and behavioural inflexibility. Nat Commun 10:3455.

Silva JM, Ezhkova E, Silva J, Heart S, Castillo M, Campos Y, Castro V, Bonilla F, Cordon-Cardo C, Muthuswamy SK, Powers S, Fuchs E, Hannon GJ (2009) Cyfip1 is a putative invasion suppressor in epithelial cancers. Cell 137:1047-1061.

Tronche F, Kellendonk C, Kretz O, Gass P, Anlag K, Orban PC, Bock R, Klein R, Schütz G (1999) Disruption of the glucocorticoid receptor gene in the nervous system results in reduced anxiety. Nat Genet 23:99-103.

van der Zwaag B, Staal WG, Hochstenbach R, Poot M, Spierenburg HA, de Jonge MV, Verbeek NE, van't Slot R, van Es MA, Staal FJ, Freitag CM, Buizer-Voskamp JE, Nelen MR, van den Berg LH, van Amstel HK, van Engeland H, Burbach JP (2010) A co-segregating microduplication of chromosome 15q11.2 pinpoints two risk genes for autism spectrum disorder. Am J Med Genet B Neuropsychiatr Genet 153B:960-966.

Verma S, Han SP, Michael M, Gomez GA, Yang Z, Teasdale RD, Ratheesh A, Kovacs EM, Ali RG, Yap AS (2012) A WAVE2-Arp2/3 actin nucleator apparatus supports junctional tension at the epithelial zonula adherens. Mol Biol Cell 23:4601-4610.

von der Lippe C, Rustad C, Heimdal K, Rødningen OK (2011) 15q11.2 microdeletion: seven new patients with delayed development and/or behavioural problems. Eur J Med Genet 54:357-360.

Wang PS, Chou FS, Ramachandran S, Xia S, Chen HY, Guo F, Suraneni P, Maher BJ, Li R (2016) Crucial roles of the Arp2/3 complex during mammalian corticogenesis. Development 143:2741-2752.

Yoon KJ, Nguyen HN, Ursini G, Zhang F, Kim NS, Wen Z, Makri G, Nauen D, Shin JH, Park Y, Chung R, Pekle E, Zhang C, Towe M, Hussaini SM, Lee Y, Rujescu D, St Clair D, Kleinman JE, Hyde TM, et al. (2014) Modeling a genetic risk for schizophrenia in iPSCs and mice reveals neural stem cell deficits associated with adherens junctions and polarity. Cell Stem Cell 15:79-91. 